1 Forest Ecosystems

2 Research Article

3

\title{
$4 \quad$ Wind and gravity in shaping Picea trunks
}

5

6 Markku Larjavaara ${ }^{1 *}$, Mikko Auvinen $^{2}$, Anu Kantola ${ }^{3}$, Annikki Mäkelä $^{4}$

7

$8 \quad{ }^{1}$ Institute of Ecology and Key Laboratory for Earth Surface Processes of the Ministry of

9 Education, College of Urban and Environmental Sciences, Peking University, Beijing

$10 \quad 100871$, China

$11{ }^{2}$ Atmospheric Dispersion Modelling, Atmospheric Composition Research, Finnish

12 Meteorological Institute, Finland

$13{ }^{3}$ Natural Resources Institute Finland (Luke), P.O.Box 2 (Latokartanonkaari 9), FI-00791

14 Helsinki, Finland

$15{ }^{4}$ Department of Forest Sciences, P.O.Box 27 (Latokartanonkaari 7), 00014 University of

16 Helsinki, Finland

17

$18 *$ Corresponding author (markku@pku.edu.cn)

19 


\section{Abstract}

22 Background:

23 Understanding why trunks (tree stems) are the size that they are is important. However, this

24 understanding is fragmented into isolated schools of thought and has been far from complete.

25 Realistic calculations on minimum trunk diameters needed to resist bending moments caused

26 by wind and gravity would be a significant step forward. However, advancements using this

27 biomechanical approach have been delayed by difficulties in modelling wind gusts. We felled and measured five Norway spruces (Picea abies) in an unthinned monoculture in southeastern Finland planted 67 years earlier. We focused on forces working on storm-bent (maximally bent) trees caused by gravity and the strongest gust in a one-hour simulation with a large-eddy simulation model.

32 Results:

33 The three largest trees resisted mean above-canopy wind speeds ranging from $10.2 \mathrm{~m} \mathrm{~s}^{-1}$ to $12.7 \mathrm{~m} \mathrm{~s}^{-1}$ (3.3-fold in the gust), but the two smallest were well protected by a dense layer of 35 leaves from the bending tops of larger trees, and could have resisted stronger winds. Gravity caused approximately one quarter of the critical bending moments.

37 Conclusions:

Our biomechanical modelling of trunk taper based on wind and gravity leads to diameters close to those measured, and we discuss the potential causes of the deviations. This approach could also be used to model tree biomasses and how those may change with changing

41 climate.

43 Keywords:

44 Gravity, Norway spruce (Picea abies [L.] Karst.), Sail area, Stem, Trunk taper, Wind drag, 45 Wood 
Many laymen agree that understanding why trees and their trunks (stems) are the size that

they are is important for evaluating the potential of forests to mitigate climate change and produce timber. They would probably be surprised to learn how fragmented the scientific understanding of tree height and diameters along the trunk are. A question concerning the dimensional determinants of a particular tree trunk may cause surprise and be considered too general by experts in narrow fields, even though understanding trunk dimensions should be considered one of the largest questions in applied ecology.

Research on trunk dimensions can be classified in two ways. Firstly, studied trees vary from those experiencing natural successions (Anderson-Teixeira et al. 2013) to those in tallest oldgrowth forests (Van Pelt et al. 2016) and to those in plantations subject to self-thinning (Yoda et al. 1963) or silvicultural treatments (Bianchi et al. 2020). Secondly, the majority of research on trunk dimensions in forest sciences and research related to forests' role in climate change mitigation is mainly descriptive (e.g. Chave et al. 2014), while much of the physiological and ecological research attempts to explain the causes of the described patterns based on theories. These theories may be grouped based on the function on which the focus is: transportation, storage or biomechanical support as explained in the following paragraphs.

66 Trees passively transport sap (water) up in the sapwood, and the resistance caused by length of the path or height difference has been used as the basis for modelling maximum tree height (Koch et al. 2004) and growth deceleration in plantations (Ryan and Yoder 1997). However, as the heartwood is not contributing to sap transportation, diameters along the trunk cannot be understood based on sap transportation only, unless heartwood is considered a waste 
produced e.g. because of ageing (Collalti et al. 2019) or difficulties in using the same sapwood when branches die and grow (Chiba et al. 1988). Phloem transportation down the trunk may be similarly limiting tree height due to path length (Woodruff 2013), but does not explain diameters, unless trunk circumference needs to be increased to increase transport capacity.

Trees are dependent on the storage of water (Scholz et al. 2011) and energy (Schiestl - Aalto et al. 2015) in their woody tissues and this is likely to influence trunk dimensions in certain conditions. For example, baobab (Adansonia digitata) trees probably have unusually fat trunks to store water needed to level out seasonal variation in water availability (Chapotin et al. 2006), and lignotubers located at the trunk base can store energy and nutrients enabling rapid sprouting (Canadell and López - Soria 1998). Trunk dimensions are therefore potentially influenced by storage needs, but this is unlikely to be common and may be restricted to trees that do not form metabolically dead heartwood and therefore cannot increase sapwood volume by adjusting the sapwood-to-heartwood-ratio such as the abovementioned baobabs (Patrut et al. 2010).

The third general function of trunks in addition to transport and storage, and the only for which heartwood is useful, is to biomechanically support the leaves, branches and trunk sections above the height at which the focus is. Two very different mechanisms may serve as a basis for modelling trunk dimensions. Elastic buckling (Euler buckling) can permanently bend trunks if the tree fresh mass and permanent loads, such as epiphytes and lianas, exceed the limit that the trunk can support. Modelling can be performed easily (McMahon 1973), and normally a "safety factor" is computed describing how far the height of the tree is from a height that leads to buckling. This approach has been used in well-known modelling 
approaches (West et al. 1999). However, most trees, with the exception of certain rainforest understorey trees, are far from elastic buckling. Furthermore, the safety factor is a misleading concept and should not be interpreted as an indication of biomechanical safety. A safety margin is needed for engineer-designed structures, as they are built and then need to resist variable forces without subsequent adjustments to the structure. However, trees can tune their structure (Bonnesoeur et al. 2016) and a small safety factor is therefore not dangerous, as supporting tissue can be increased simultaneously according to demand from the increasing height or crown weight. The wide usage of the theory on elastic buckling shocked Mattheck (2012) and he wrote: "Much to the surprise of the author, failure by buckling has nevertheless been discussed by McMahon (1973), and comparisons have been made between measured height-diameter relations and relations calculated from Euler's buckling theory." The other, more useful, biomechanical approach is based on trunks breaking (snapping). Temporary buckling may not be a problem for the tree if it recovers and is erect most of the time, but when modelling trunk breakage, even a short period may be fatal and wind loads are therefore central. This modelling approach is challenging to follow, as wind speeds are variable in space and time, and trunks, branches and leaves streamline in wind. In both buckling and breaking approaches, biomechanics are setting the diameters needed along the trunk for a given height and other characteristics, but do not limit height if the diameters are not limited.

All trees need trunks to transport, to provide biomechanical support and probably also to store, and theories and modelling to understand trunk dimensions should ideally incorporate all of these with appropriate weights. However, in practice realistic modelling of even one of these aspects at a time is challenging. Therefore, it is useful to consider their relative importance. One challenge is that scientists are often experts on only one of these three 
functions. Secondly, if building or maintaining a trunk that is superior in any of the three functions causes an energetic cost, all functions would evolve close to the needed level even if the cost improving it relative to the others would be minuscule. An example with an engineer-designed product demonstrates this issue well. An expert focusing on tires may conclude that a given car cannot go faster than e.g. $50 \mathrm{~m} \mathrm{~s}^{-1}$ because of the speed rating of the tires. According to an expert on engines the top speed of the same car is restricted by engine power. Both would be technically correct, but to understand the main reason why markets set the top speed at its level, the challenges in designing, manufacturing, maintaining and operating engines and tires that allow faster speeds must be considered. This reveals that, as improving the speed rating of tires is very easy relative to designing and building a more powerful engine, it makes normally more sense to say that the car does not go faster because the engine is not more powerful and not because of its tires. Similarly, demonstrating that e.g. transporting sap higher than the current height of the tallest trees (Koch et al. 2004) does not necessarily mean that sap transportation is the main factor determining maximum heights. Instead, in evolutionary time scales for example sap transportation capacity could improve to a height determined mainly by the biomechanics and energetics of maintaining the living biomass.

We did not properly assess the relative importance of how the functions of trunks influence their dimensions, as that would need to be done by incorporating them into one model. In this paragraph, we just note a few pieces of evidence that indicated to us the direction to take. One approach is to consider the marginal construction and maintenance costs of increasing capacity. Tissue suitable for storage or sap transport may be increased by increasing sapwood and decreasing heartwood proportions. Furthermore, sap transport efficiency may be boosted by increasing the density of conduits, probably with little or no additional construction costs 
146 (Larjavaara submitted manuscript). However, significant strengthening of the trunk is not 147 possible without substantial additional construction costs, either by increasing diameters or wood density (Larjavaara and Muller-Landau 2012). Another approach is to compare tree trunk dimensions in variable environmental conditions that demand for variable transport, storage and biomechanical support needs. This approach underlines the importance of sap transport if height and diameters along the trunk vary according to water availability. The very tallest trees would then be expected to be found in climates and soils with most abundant water, which is not the case, even though the driest climates have a low canopy height (Klein et al. 2015). If storage function was critical in determining trunk dimensions, then seasonality should increase trunk volumes relative to leaf area, which may be case (Chapotin et al. 2006) but probably only in the case of exceptional species. Finally, with biomechanical support being the most significant, tree heights and forest biomasses should vary depending on winds. This is the case for example with variable distances from the edge and therefore variable wind regimes (Brüchert and Gardiner 2006). Another perspective on the importance of biomechanics is provided by comparing trees to lianas, which do not have the same biomechanical support needs. Lianas have similar transport and storage needs as trees, and much higher leaf area for a given stem basal area (Ichihashi and Tateno 2015), which is very likely due to differing biomechanical needs, highlighting their importance to trunk dimensions. These considerations led us to explore the role of wind forces and gravity as key determinants of trunk dimensions, which is the focus of this article.

The importance of wind and gravity as a cause of trunk breakage is perhaps what common sense would suggest to be the main factor explaining trunk dimensions. This approach was pioneered in the $19^{\text {th }}$ century (Metzger 1893) and regularly discussed (Mäkelä 2002). 
methodological challenges from variable winds and the streamlining mentioned above and due to rarity of the strongest storms that are critical for tree survival and therefore probably drive evolution. Interesting studies are available on small trees secured on the roof of a moving car (Butler et al. 2012) and medium-sized trees during the leafless period (Niklas and Spatz 2000), but small (Larjavaara 2015) and leafless (Mattheck 2000) trees have different biomechanical constraints than large foliated trees. Large foliated trees have also been examined in impressive studies representing simple (Morgan and Cannell 1994), more realistic (Spatz and Bruechert 2000) or excellent detail in tree dimensions (Jackson et al. 2019). However, none of these studies focused on maximally bent trees.

The objective of this study was to increase our comprehension of determinants concerning tree size and trunk taper, as modified by selective pressures caused by exposure to stormstrength winds, and to examine whether trees are adapted and acclimatized to those. To this end, we modelled wind in a canopy of a mature storm-bent stand and computed gravity- and wind-caused forces on segments along the trunks based on destructive sampling of Picea gust.

\section{Methods}

Picea abies is a common tree species in its natural range of Northern Europe and Central America (Caudullo et al. 2016). In Finland, Picea abies trunk volumes make up 30\% of all 
tree trunk volumes and the volume of harvested trees is $38 \%$ of total (Peltola 2014). It regenerates in intermediate or fertile soils, is the most shade tolerant of the main tree species in Finland and will therefore invade all but the most infertile sandy or peat soils when sufficient time since disturbance has passed (Kuuluvainen and Aakala 2011). Picea abies trees have a straight trunk and long conical crown often reaching the ground. In Finland, the lower branches shed from the lower crown layers in the deep shade of conspecifics. New branches develop annually, forming whorls of branches. Its wood is of low or intermediate in density at, especially when compared to angiosperms (Chave et al. 2009).

We based our study on data collected in 2001 to investigate crown development in three sites around southern Finland in stands after canopy closure (Kantola and Mäkelä 2004). However, to reduce the complexity of wind gust-related analysis, only a single plot featuring flat terrain is included in this study. The other plots were excluded because of hilly terrain, which alters low-altitude winds in a complex manner (Gardiner et al. 2016). The included plot, described in more detail by Kantola and Mäkelä (2004), was located in Punkaharju at $61^{\circ} 49^{\prime} \mathrm{N}$, $29^{\circ} 19^{\prime} \mathrm{E}$, now part of Savonlinna in southeastern Finland. The local climate is conducive to tree growth, as abundant lakes level out temperature fluctuations during the growing season. The soils in the plot are well above average fertility for the region, classified as Oxalis-type (Cajander 1949), leading to a site index, $\mathrm{H}_{100}$ of $32 \mathrm{~m}$. The monoculture of Picea abies trees was planted 67 years prior to data collection.

Three stands with varying thinning histories were studied in the plot but two were excluded from our study because of thinnings, as explained below. The included unthinned stand had a basal area of $44 \mathrm{~m}^{2} \mathrm{ha}^{-1}$ and stand density of $805 \mathrm{ha}^{-1}$. Five sample trees representing various canopy layers were felled, and their trunks, branches and leaves (i.e. needles) were measured 
and weighed as described in detail by Kantola and Mäkelä (2004). In summary, trunk diameters were measured immediately below each whorl of branches, and all branches were cut and measured and a subset of them taken to a laboratory for more detailed measurements. The heights and diameters of the five trees at a 1.3-m height $\left(\mathrm{d}_{1.3}\right)$ can be seen in Fig. 7 in the Results section. The percentage of the trunk with leaving branches of the five sample trees differed between 42-63, being greatest for dominant trees and smallest for trees grown in more suppressed positions. And further, the more suppressed, i.e. thin, trees also had the lightest-weight crowns compared to more dominant ones, which was consistent with the pipe model theory (Kantola and Mäkelä 2004).

For this study, we divided the five tree trunks into "segments" and estimated the bending, location relative to the base of the tree, projected area perpendicular relative to wind direction (i.e. frontal area) and fresh mass for each of them. We assumed the centre of each segment to be in the whorl of branches and extremes to be located half way between neighbouring whorls. We divided the unmeasured lower branchless trunk into four segments, with the lowest centred at a height of $1.3 \mathrm{~m}$, the remaining three at regular intervals between $1.3 \mathrm{~m}$ and the lowest whorl and assumed diameter to simply change linearly, as we anticipated this lowest part of the trunk to contribute only little to the bending moments.

The streamlining of trees is complex, and therefore the common approach is to simulate upright trees but with reduced wind drag estimated with a coefficient (Gardiner et al. 2016). We instead focused on the strongest gust and "storm-bent" trees, i.e. trees bent along their trunks as much as they can without breaking (see Fig. 5). This focus was based on the reasoning that even though acclimation is likely to be mainly driven by signals from normal wind speeds (Bonnesoeur et al. 2016), trunks are probably tuned to resist the strongest gusts 
based on normal winds. Maximum strain in both compression and tension may be assumed to equal the ratio of modulus of rupture and modulus of elasticity. In a bending segment or cylinder, the maximum tension occurs in the outermost fibres of the convex side and maximum compression in the innermost fibres of the concave side. Further assuming that wood follows Hooke's law (Vogel 2013) in both compression and tension, the additional bending of each segment in a storm $(\alpha)$ is:

252

$$
\alpha=\sin ^{-1} \frac{2 l \sigma}{d E}
$$

where $l$ is the length of the segment, $\sigma$ the modulus of rupture obtained from tree-pulling experiment is 36.26 Mpa (Peltola et al. 2000), $d$ the diameter of the segment at its centre and $E$ the modulus of elasticity is $7730 \mathrm{Mpa}$ (Peltola et al. 2000).

We used the projected area of trunks, branches and leaves (we call their sum "sail area") first for estimating wind speeds and then to compute wind-caused horizontal forces (Additional file).

In addition to the five felled trees, we measured the $\mathrm{d}_{1.3}$ of all trees less than seven metres away from the felled ones. We estimated their sail area and its vertical storm-bent distribution by fitting two simple linear regressions to the variables. We then first computed the stormbent height based on the model in Fig. 1 and then its sail area based on the model in Fig. 2, in which a linear relationship was expected based on biomechanics, as the toppling over moment is expected to scale roughly with the product of the sail area and the length of the lever (tree height) and the strength of the trunk with the cube of its diameter (Ennos 2012). We plotted these models for all three stands, but observed the fit to be tight in the unthinned plot 
only. We surmised that as the previous thinning occurred only 14 years prior to the measurement, the trunk dimensions relative to the sail area (Additional file) were possibly still unbalanced because of too little time since the thinning. We therefore excluded these stands from the analysis. The mean $\mathrm{d}_{1.3}$ of the five felled trees was $0.272 \mathrm{~m}$ and they ranged from $0.213 \mathrm{~m}$ to $0.328 \mathrm{~m}$, while the surrounding trees around these five had a mean of 0.260 $\mathrm{m}$ and a range from $0.167 \mathrm{~m}$ to $0.382 \mathrm{~m}$. Because of the tight fit of models in Fig. 1 and Fig. 2, we do not think that extrapolating to some distance out of the range was likely to cause a significant bias.

We wanted to focus on strongest winds that the trees can stand and therefore used simulated winds. Because of significant horizontal movement of trees in gusts we had to assume that the forest canopy had a horizontally homogenous sail area and therefore sail area per unit volume (i.e. plant area density) for each 1.5-m thick layer. The large-eddy Simulation model PALM (Maronga et al. 2015) was employed to obtain a time-accurate and spatially resolved description of fully developed boundary layer turbulence over continuous forest canopy. The PALM model is specifically tailoured for atmospheric boundary layer turbulence applications and has been optimized for massively parallel supercomputing environments. The model implements the conservation equations governing atmospheric boundary layer turbulence employing finite-difference discretization on a staggered Cartesian grid. The system of equations is solved using a third-order accurate Runge-Kutta time-stepping scheme and fifthorder accurate upwind biased spatial discretization scheme (Wicker and Skamarock 2002). The forest canopy is modelled as a porous homogenous medium whose porosity is dictated by the vertical sample-averaged plant area density distribution of the trees. 
Aa vast majority of the drag caused by the forest canopy was assumed to be pressure drag, and therefore the drag force $(f)$ is implemented in PALM as:

$$
\vec{f}=C_{d} P|\vec{u}| \vec{u},
$$

where $C_{d}$ is the drag coefficient for forest canopy, $P$ is the vertical plant area density profile of the forest, and $\vec{u}$ is the spatially and temporally resolved wind velocity vector whose magnitude is denoted as $|\vec{u}|$. We set $C_{d}$ at 0.2 as suggested by Katul (1998). The wind simulations were performed on a rectangular domain with $L x$ of $3.84 \mathrm{~km}, L y$ of $1.28 \mathrm{~km}$ and $L z$ of $0.52 \mathrm{~km}$ as streamwise, lateral and vertical dimensions, respectively. Wind was driven with a prescribed pressure gradient at $\mathrm{z}>250 \mathrm{~m}$, allowing the lower-altitude flow to attain a constant momentum flux layer, which is characteristic for atmospheric boundary layer flows (Stull 2012). The magnitude of the pressure gradient was set sufficiently high to achieve very high Reynolds number conditions, which ensures that the associated turbulence solution attains a state that is independent of wind speed. That is, if the wind speed were further increased, the turbulent structures and dynamics would remain statistically identical. This Reynolds number independence allows one representative turbulent wind solution to be freely scaled (especially upward) to represent other wind conditions. The simulation for the (scalable) reference wind was initially run for one hour to allow the flow to reach a statistically stationary state. The simulation was then continued for an additional hour during which detailed wind velocity time series is collected every $3 \mathrm{~s} \mathrm{(at} \mathrm{1/3} \mathrm{Hz)} \mathrm{across} \mathrm{the} \mathrm{entire}$ depth of the forest canopy from a $0.5-\mathrm{km}^{2}$ monitoring plane. This time series contains a sample of $105.6 \times 10^{6}$ instantaneous wind events impacting the forest canopy. As the main interest is on gusts whose duration is sufficient to cause further displacements in the tree trunks, two consecutive wind events are averaged to yield a conservative approximation for a 
3-s gust. Thus, the time series contained approximately $50 \times 10^{6}$ gust events, which were considered a sufficiently large sample size to capture rare gust events that impose the largest risk for trunk failure. The gust events causing the maximal bending moments were searched by considering the forest canopy to contain trees with uniform horizontal cross-sections (just for the sake of wind gust analysis). The bending moment for each model tree was computed for all 3-s gust events and the maximum events (time and location) were stored. The wind speed profile spanning across the tree height was then obtained from this location and instance. The selected gust event provided the most realistic estimation for the critical velocity distribution during a probable failure event.

In addition to the normal simulation named "Dense", we performed secondary simulations with half of the sail area removed from all heights above ground (i.e. "Thinned") and trunks and branches remaining but leaves removed (i.e. "Leafless"). However, it is important to note that these two secondary simulations violate the basis of our modelling of trees evolved to withstand a given above-canopy wind speed by equal strain along the trunk, as a sudden thinning or defoliation would disturb the balance to which trees have acclimated and trunks would therefore likely break before full bending is reached.

We computed the bending moments by adding moments from all segments above the segment in question (Fig. 3). We obtained the weights, i.e. the vertical forces, by adding water contents of 0.79 for the trunk, 1.41 for the branches and 2.24 for leaves (Kärkkäinen 1985) to the dry masses (Kantola and Mäkelä 2004) and multiplying by the gravity constant $\left(9.82 \mathrm{~m} \mathrm{~s}^{-2}\right)$. The critical bending moment, i.e. the maximum bending moment that a cylindrical trunk segment can resist $\left(m_{r}\right)$ is: 


$$
m_{r}=\frac{\sigma \pi d^{3}}{32}
$$

344 where $\sigma$ is modulus of rupture and $d$ is the diameter of the segment (Ennos 2012). The sum of

gravity- and wind-caused bending moments that cause this same $m_{r}$ for the trunk segment is:

346

$$
m_{r}=r^{2} \sum m_{u}+\sum m_{g}
$$

347

348

349

350

351

352

353

354

355

356

357

358

359

360

361

362

363

364

7

8

where $\sum m_{g}$ is the sum of all gravity-caused bending moments of all the segments above,

$\sum m_{u}$ is the sum of all wind-caused bending moments from segments above in a reference above-canopy mean wind speed and $r$ is the ratio of the maximum and reference (to compute $\sum m_{u}$ ) mean above-canopy wind speeds based on the wind profile obtained from the PALM model. We then computed critical wind speeds and required diameters based on equations 3 and 4.

We did not "tune" the approach or parameters to obtain a desirable fit. Below, we report the results from the analysis planned before beginning analysing the data.

\section{Results}

Most of the sail area of the five felled trees is caused by leaves and is located, once the trees are storm-bent, at a height of 15-21 m (Fig 4a). When the surrounding trees are added, the "blanket" of sail area thickens, mainly upward (Fig 4b), but is still surprisingly thin for a tree species having an unusually long crown. The lack of thinnings in the studied stand has 
probably thinned the "blanket" by both lifting the height of the lowest living branch but also by decreasing diameters and therefore increasing bending in gusts.

The gust wind speeds are weak below $8 \mathrm{~m}$, and increase roughly linearly upwards through the main sail area in Dense and Thinned stands (Fig. 4c). However gust wind is significant down to the ground in the Leafless stand (Fig. 4c).

The weight of the branchless lower parts of the trunks of all five felled trees is important, but they cause bending moments only to the lower segments of the trunk. These moments are small, as the segments are nearly vertically aligned (Fig. 5). The gravity-caused forces from the upper segments that produce potentially more significant bending moments are roughly evenly divided by those caused by the trunk, branches and leaves (Fig. 5). The comparison between trees illustrates how trees with larger $\mathrm{d}_{1.3}$ (Tree 4 and Tree5) have correspondingly heavier crowns but the differences are small. The differences between the five trees are much more significant when the horizontal vectors caused by wind are examined (Fig. 5). The smallest trees experience much greater forces caused by gravity than wind, whereas both forces are of the same magnitude in the crowns of the largest trees. However, the windcaused forces act higher up along the trunk and their direction also causes greater strengthening requirements for the lower trunk. Because the top of storm-bent Tree1 is only at a height of $16.1 \mathrm{~m}$, it is well protected by more rigid taller trees (Fig. 5). Interestingly, because the shorter trees bend more, the horizontal displacement caused by wind is approximately the same for all five trees, ranging from $12.7 \mathrm{~m}$ (Tree5) to 14.3 (Tree3).

Gravity from all segments above the height at which the focus is causes $18-27 \%$ of the bending moment that breaks a tree at a height of $1.3 \mathrm{~m}$ (Fig. 6). This proportion increases 
upwards to a height of $12-15 \mathrm{~m}$ with the lowest branches and then decreases down to a rounded $0 \%$ for the tops of the trees. However, as bark is included in the used $d$ and the wood characteristics are unusual for the topmost segments, the estimated proportion is likely to be a severe underestimation. Nevertheless, the proportion of gravity clearly decreases upwards in the canopy.

Fig. 7 demonstrates the dimensions of the five felled trees without wind and in addition to the measured diameters, the diameters needed to resist an above-canopy mean wind of $10.2 \mathrm{~m} \mathrm{~s}^{-1}$, which is the speed that is at the limit of breaking Tree4. This can be seen from the dotted red line touching the solid black line at a height of $13.9 \mathrm{~m}$. Tree3 and Tree5 are able to resist similar mean above-canopy wind speeds $\left(12.7 \mathrm{~m} \mathrm{~s}^{-1}\right.$ and $\left.11.3 \mathrm{~m} \mathrm{~s}^{-1}\right)$, and therefore the modelled taper is similar to the measured taper (Fig. 7). However, for Tree2 and especially Tree1, a significantly thinner trunk would be sufficient to withstand the simulated gust with an above-canopy mean wind of $10.2 \mathrm{~m} \mathrm{~s}^{-1}$. The simulated gust increases wind speeds considerably, reaching $34.2 \mathrm{~m} \mathrm{~s}^{-1}$ above-canopy (height of $29.25 \mathrm{~m}$ ) and decreasing downwards as shown in Fig. 4c, with a speed of $25.9 \mathrm{~m} \mathrm{~s}^{-1}$ in the upper part (height of 21.75 $\mathrm{m}$ ) of the storm-bent main canopy and $5.6 \mathrm{~m} \mathrm{~s}^{-1}$ in the lower part (height of $12.75 \mathrm{~m}$ ).

The above-canopy mean wind speed in the thinned stand is surprisingly similar, rounds to the same $10.2 \mathrm{~m} \mathrm{~s}^{-1}$ in the equivalent meteorological situation and is slightly weaker in the strongest gust at $33.2 \mathrm{~m} \mathrm{~s}^{-1}$. However, the winds are stronger within the canopy, and for all except Tree1, greater diameters would have been needed to resist breaking (Fig. 7), indicating that thinnings increase the risk of toppling over. 
414 The wind simulation for a leafless stand resulted in an above-canopy mean wind speed of $415 \quad 14.6 \mathrm{~m} \mathrm{~s}^{-1}$ (gust $36.3 \mathrm{~m} \mathrm{~s}^{-1}$ ) in the same meteorological situation as discussed above and the 416 wind penetrated the stand with much more force (Fig. 4c). A significantly smaller diameter

417 for all trees and along all heights would be sufficient in this situation (Fig. 7), as sail areas of 418 the trees decreased.

\section{Discussion}

We developed a novel approach to model bending and bending moments caused by wind and gravity and applied this to an unthinned middle-aged Picea stand originated from planted seedlings. We observed a close match of modelled and the actual diameters along their trunks for most of the trees (Fig. 7). Therefore, we may conclude that these bending moments are probably important in determining trunk diameter and shape, but we are unable to compare importantace of alternative determinants of tree size such as sap transport. The relatively small contribution of a tree's own mass (Fig. 6) indicates that, if to simplify only gravity or wind can be included in the modelling, wind would probably be a better choice, even in a dense unthinned stand (e.g. Larjavaara 2010) with small sail areas relative to fresh masses.

Our simulated winds may be compared to those within (at a height of $9 \mathrm{~m}$ ) and above (at a height of $23 \mathrm{~m}$ ) a 16-m tall Pinus sylvestris stand during a summer microburst that toppled over trees approximately $300 \mathrm{~m}$ from the wind measurements (Järvi et al. 2007). The microburst caused one-minute mean wind speeds of ca. $14 \mathrm{~m} \mathrm{~s}^{-1}$ above and $5 \mathrm{~m} \mathrm{~s}^{-1}$ within the canopy. The above-canopy speed is close to the winds that our five trees can resist, with the exception of TREE1 (Fig. 7). Furthermore, the wind speed within the relatively sparse Pinus 
canopy corresponds to values that may have been expected based on our wind profiles (Fig.

4c). However, the variation in windspeed measured by Järvi et al. (2007) was much lower, as

441

442

their "instantaneous" above-canopy wind speeds peaked at only just above $20 \mathrm{~m} \mathrm{~s}^{-1}$. This may indicate that our biomechanical computations overestimated the resistance of trees to bending forces. However, as the damaged Pinus trees were located some distance away, it is possible they experienced much stronger wind speeds.

Our objectives were to understand more about trunk taper based on wind and the risks that trees potentially take, whereas the majority of research linking taper, wind and risks inversely attempt to estimate risks from taper and winds (Gardiner et al. 2008). The demand for advice from forest managers is substantial both in plantations (Gardiner et al. 2016) and urban setting (Sæbø et al. 2003), and advances have been impressive (Gardiner et al. 2019). However, a pessimist may argue that scientists will never be "wiser" than an acclimated tree in understanding the local wind profile and risks caused by extreme gusts. From an evolutionary perspective, trees balance between snapping in a storm and overinvesting in trunk tissue and being overtopped by their neighbours. A winning strategy optimally balancing between the deadly "ditches" on both sides depends on the position of the other ditch. Hence, in a situation with fierce competition and high likelihood of being overtopped by neighbours, such as in middle-aged dense plantations, the risk on toppling in a storm is increased. Therefore, the most fruitful theoretical (not just statistical and descriptive) way to estimate the toppling over risk may be based on competition for height from an evolutionary perspective. Physical modelling, such as that used in this article but inversely, is more promising for trees in situations have not acclimated to, e.g. after their neighbours have been harvested (e.g. Peltola et al. 1999). 
In our simulation of the strongest gust, it is remarkable how a Picea abies monoculture, characterised by long, conical, and slender crowns, forms a relatively thin "blanket" of sail area at approximately $18 \mathrm{~m}$ above ground during a gust. To support a larger leaf mass, a tree needs to build a thicker trunk to resist the wind drag and gravity acting on this additional mass. Even without additional height when unbent, the additional diameter reduces bending and the storm-bent height increases. Because trees with thicker trunks are normally also taller, they have greater wind drag caused by bending moments because of greater sail area and this area being located in greater winds because of greater unbent height but also reduced bending. The thicker trees in a stand are responsible for blocking and protecting the smaller "biomechanical free-riders", which operate as a balancing force, i.e. negative feedback, in stand development.

Tree 1 is much thicker and Tree 2 is to some extent thicker than they need to be to resist the modelled gust. Their positions in the canopy may have weakened rapidly, leaving their thicker trunks as a legacy of a time when they needed strength for a larger leaf area, but biomechanically they would not then need new diameter growth. The transport-focused perspective offers an alternative explanation. When trees become suppressed in the canopy, they rapidly lose their lower branches and their crown length grows more slowly than their height, reducing their crown ratio. This change in growth pattern may be regarded as an evolutionary response to competition for light (e.g. Mäkelä 1985). In this process, active wood, i.e. sapwood, related to the receding branches loses its connection to the foliage and gradually turns into inactive heartwood. Empirical evidence and eco-evolutionary balance theories suggest that active wood area and foliage area are in balance with each other (Chiba et al. 1988; Mäkelä and Valentine 2006; Shinozaki et al. 1964). Losing the active wood related to the receding branches therefore creates a need for new diameter growth, as the 
existing inactive wood can no longer be used for water transport. If we assume that all these selective pressures, related to biomechanics, water transport, and competition for light, are present in the tree population, then our results suggest that biomechanics dominate trunk dimensions of dominant trees (see also Mäkelä and Valentine 2006), while with suppressed trees the balance has shifted from biomechanics towards sap transportation. Another reason for our result that smaller trees have larger diameters than apparently necessary may be that our wind model severely overestimates the steepness of the vertical wind profile. It is also possible that supressed trees occasionally experience unusually strong gusts that penetrate the canopy and are therefore seemingly overbuilt. If suppressed trees are biomechanically overbuilt because of sap transport, they would be expected to survive storms more likely than dominants, but if they are not biomechanically overbuilt they may on the contrary be more vulnerable due to greater risk-taking.

501

The tops of all five trees appear overbuilt. We can try to understand this by comparing small trees of the same height that may initially seem to have nearly identical biomechanical constraints. Coincidentally, both small Picea trees and residue treetops have commonly been used as Christmas trees in Finland and are easy to differentiate even from a distance. Treetops need to resist much stronger winds but can streamline easier, as their bases are tilted thanks to the bending lower trunk. Probably most importantly, treetops cannot rely on the "shrub strategy" of bending all the way to the ground to remain unharmed (Larjavaara 2015). This makes small trees resistant to the strongest winds and heaviest snowloads, as they can bounce back after a gust has passed or the snow has melted. Treetops however, cannot rely on ground support during gusts, but this is probably not a problem for the well-streamlined tops of Picea 512 abies (Fig. 5). Snow weight, which may be significant in the region, is a possible reason for 
the seemingly overbuilt tops in our dataset (Peltola et al. 1999), especially when temperatures are close to freezing or when direct condensation occurs on trees.

515

We focused on an unthinned boreal monoculture, i.e. nearly the simplest stand imaginable only treetops could potentially have been easier to understand in an ice-free climate. We nevertheless had to make many simplifying assumptions, some of which potentially bias our results dangerously. The risk of resonating with the wind is a serious concern in designing structures, such as bridges, and the risk of trees swaying with a pulsing wind has often been the focus of trunk breakage literature (Niklas and Spatz 2012). However, air flow modelling does not seem to create such winds (Gardiner et al. 2019) and is rarely seen in dozens of videos found on the Internet that depict uprooting or trunk breakage (ML personal observation). Similarly, torsional forces have attracted some attention (Skatter and Kucera 2000), but we may ask why evolution would not have strengthened trunks to resist twisting if it was really the main mode of trunk failure. Uprooting possibly being more common than trunk breakage is one argument against the biomechanical modelling of trunks, but this does not rule out the importance of trunk dimensions on trunk failure. In their evolutionary history, trees have probably balanced the risks of uprooting and trunk breakage depending on the level and variability of risks and on the cost of strengthening them. Our assumptions that the same level of streamlining occurs at all heights (Additional file) and invariable, modulus of rupture $(\sigma)$ and modulus of elasticity $(E)$, may be far from realistic but probably do not interfere significantly with our comparison between trees and along the trunk of one tree.

534 Choosing the value for drag coefficient $\left(C_{d}\right)$ was rather arbitrary as always. Furthermore, we did not attempt to include physical contact with neighbours influencing the bending forces. 
539 Our greatest concern relates to dealing with streamlining and the homogeneousness of the sail 540 area. We assumed 50\% streamlining for branches and none for leaves (Additional file). This

541 is probably an underestimation (Peltola et al. 1999), but perhaps surprisingly it does not

542 strongly influence this kind of analysis, as despite streamlining reducing wind drag caused by

543 a given wind speed, it increases wind speeds within the stand. For example, the Thinned

544 simulation with half of the sail area removed corresponds to the Dense simulation with

545 streamlining reducing the projected area to half its original size. This allows us to estimate

546 the sensitivity of our results to assumptions on streamlining. Interestingly, the wind-caused

547 bending moments were larger for two of our five trees, with $50 \%$ stronger streamlining,

548 while they were smaller for three trees. This indicates that our results are not very sensitive to

549 streamlining, as the increasing wind speed due to streamlining compensates for the reduced

550 sail area. Similarly, the spatial grouping of sail area is probably important and drastically

551 influences both winds and the drags that they cause. However, again it is possible that

552 reduced winds for a given wind speed cause greater within-canopy winds thanks to the

553 clustering of sail area, and their impacts may roughly even out as with the cause of

554 streamlining.

555

556 Our approach could be utilized in several applications. Evolutionary simulations could 557 optimize trunk dimensions by considering the benefits of being a biomechanical free-rider 558 and trusting larger neighbour trees to withstand wind, but potentially face local extinction if 559 all canopy species or individuals take excessive risks and rely on others not toppling over. 560 Other mechanistic modelling approaches (Kalliokoski et al. 2016), which are potentially 561 especially valuable when optimizing forest management in changed conditions, may also 
563 increasing detail in the direction pointed by Eloy et al. (2017).

564

565 List of abbreviations

566 Not applicable.

567

568

Declarations

569

570 Ethics approval and consent to partipate

571 Not applicable.

572

\section{Consent for publication}

574 Not applicable.

575

576 Availability of data and materials

577 The dataset will be made available in a location specified later.

578

579 Competing interests

580 The authors declare that they have no competing interests.

581

$582 \quad$ Funding

583 ML acknowledges Peking University for funding.

584

585 Author's contributions 
586 ML and AM developed the research idea, AK designed and implemented the data collection 587 procedure supervised by AM, MA performed the wind simulations and wrote the first draft of 588 its description, ML performed the other analyses, prepared the figures and wrote the first 589 draft of the other sections, and all authors participated in producing the final version of the 590 manuscript.

591

592 Acknowledgements

593 We thank Tapio Linkosalo for discussions in the early stages of the research process and 594 Stella Thompson for English language editing. 


\section{References}

596

Anderson-Teixeira KJ, Miller AD, Mohan JE, Hudiburg TW, Duval BD, DeLucia EH (2013) Altered dynamics of forest recovery under a changing climate Global Change Biology 19:2001-2021 doi:10.1111/gcb.12194

600

Bianchi S, Huuskonen S, Siipilehto J, Hynynen J (2020) Differences in tree growth of Norway spruce 601 under rotation forestry and continuous cover forestry Forest Ecology and Management 458

Bonnesoeur V, Constant T, Moulia B, Fournier M (2016) Forest trees filter chronic wind - signals to acclimate to high winds New Phytol 210:850-860

Brüchert F, Gardiner B (2006) The effect of wind exposure on the tree aerial architecture and 605 biomechanics of Sitka spruce (Picea sitchensis, Pinaceae) American journal of botany 93:1512-1521

Butler DW, Gleason SM, Davidson I, Onoda Y, Westoby M (2012) Safety and streamlining of woody 608 609 shoots in wind: an empirical study across 39 species in tropical Australia New Phytol $193: 137-149$

610

Cajander AK (1949) Forest types and their significance Acta Forestalia Fennica 56:1-72

Canadell J, López - Soria L (1998) Lignotuber reserves support regrowth following clipping of two Mediterranean shrubs Functional Ecology 12:31-38

Caudullo G, Tinner W, de Rigo D (2016) Picea abies in Europe: distribution, habitat, usage and

Chapotin SM, Razanameharizaka JH, Holbrook NM (2006) Baobab trees (Adansonia) in Madagascar use stored water to flush new leaves but not to support stomatal opening before the rainy season New Phytol 169:549-559 doi:10.1111/j.1469-8137.2005.01618.x economics spectrum Ecology Letters 12:351-366 doi:10.1111/j.1461-0248.2009.01285.x 
621

622

623

624

625

626

627

628

629

630

631

632

633

634

635

636

637

638

639

640

641

642

643

644

Chave J et al. (2014) Improved allometric models to estimate the aboveground biomass of tropical trees Global Change Biology 20:3177-3190 doi:10.1111/gcb.12629

Chiba Y, Fujimori T, Kiyono Y (1988) Another interpretation of the profile diagram and its availability with consideration of the growth process of forest trees Journal of the Japanese Forestry Society $70: 245-254$

Collalti A et al. (2019) Plant respiration: controlled by photosynthesis or biomass? Global Change Biology

Eloy C, Fournier M, Lacointe A, Moulia B (2017) Wind loads and competition for light sculpt trees into self-similar structures Nat Commun 8:1014

Ennos AR (2012) Solid biomechanics. Princeton University Press,

Gardiner B, Achim A, Nicoll B, Ruel J-C (2019) Understanding the interactions between wind and trees: an introduction to the IUFRO 8th Wind and Trees Conference (2017) Forestry: An International Journal of Forest Research 92:375-380

Gardiner B, Berry P, Moulia B (2016) Wind impacts on plant growth, mechanics and damage Plant Science 245:94-118

Gardiner B, Byrne K, Hale S, Kamimura K, Mitchell SJ, Peltola H, Ruel J-C (2008) A review of mechanistic modelling of wind damage risk to forests Forestry: An International Journal of Forest Research 81:447-463

Ichihashi R, Tateno M (2015) Biomass allocation and long - term growth patterns of temperate lianas in comparison with trees New Phytol 207:604-612

Jackson T et al. (2019) Finite element analysis of trees in the wind based on terrestrial laser scanning data Agricultural forest meteorology 265:137-144

Järvi L et al. (2007) Micrometeorological observations of a microburst in southern Finland. In: Atmospheric Boundary Layers. Springer, pp 187-203 
Kalliokoski T, Mäkinen H, Linkosalo T, Mäkelä A (2016) Evaluation of stand-level hybrid PipeQual model with permanent sample plot data of Norway spruce Canadian Journal of Forest Research 47:234-245

Kantola A, Mäkelä A (2004) Crown development in Norway spruce [Picea abies (L.) Karst.] Trees Structure \& Functioning 18:408-421

Kärkkäinen M (1985) Puutiede. Sallisen kustannus,

Katul G (1998) An investigation of higher-order closure models for a forested canopy Boundary-Layer Meteorology 89:47-74

Klein T, Randin C, Korner C (2015) Water availability predicts forest canopy height at the globalscale Ecology Letters 18:1311-1320 doi:10.1111/ele.12525

Koch GW, Sillett SC, Jennings GM, Davis SD (2004) The limits to tree height Nature 428:851-854 doi:10.1038/nature02417

Kuuluvainen T, Aakala T (2011) Natural forest dynamics in boreal Fennoscandia: a review and classification Silva Fennica 45:823-841

Larjavaara M (2010) Maintenance cost, toppling risk and size of trees in a self-thinning stand Journal of Theoretical Biology 265:63-67

Larjavaara M (2015) Trees and shrubs differ biomechanically Trends Ecol Evol 30:499-500 doi:http://dx.doi.org/10.1016/i.tree.2015.07.007

Larjavaara M, Muller-Landau HC (2012) Still rethinking the value of high wood density American Journal of Botany 99:165-168 doi:10.3732/ajb.1100324

Mäkelä A (1985) Differential games in evolutionary theory: height growth strategies of trees Theoretical Population Biology 27:239-267

Mäkelä A (2002) Derivation of stem taper from the pipe theory in a carbon balance framework Tree Physiology 22:891-905

Mäkelä A, Valentine HT (2006) Crown ratio influences allometric scaling in trees Ecology Letters $87: 2967-2972$ 
671

672

673

674

675

676

677

678

679

680

681

682

683

684

685

686

687

688

689

690

691

692

693

694

695

696

Maronga B et al. (2015) The Parallelized Large-Eddy Simulation Model (PALM) version 4.0 for atmospheric and oceanic flows: model formulation, recent developments, and future perspectives Geoscientific Model Development Discussions 8

Mattheck C (2000) Comments on" Wind-induced stresses in cherry trees: evidence against the hypothesis of constant stress levels" by KJ Niklas, H.-C. Spatz, Trees (2000) 14: 230-237 Trees Structure \& Functioning 15

Mattheck GC (2012) Trees: the mechanical design. Springer Science \& Business Media,

McMahon T (1973) Size and shape in biology Science 179:1201-1204

Metzger K (1893) Der Wind als maßgebender Faktor für das Wachsthum der Bäume Mündener Forstliche Hefte 5:35-86

Morgan J, Cannell MG (1994) Shape of tree stems-a re-examination of the uniform stress hypothesis Tree physiology 14:49-62

Niklas KJ, Spatz H-C (2000) Wind-induced stresses in cherry trees: evidence against the hypothesis of constant stress levels Trees Structure \& Functioning 14:230-237

Niklas KJ, Spatz HC (2012) Plant Physics. University of Chicago Press,

Patrut A et al. (2010) Fire history of a giant African baobab evinced by radiocarbon dating Radiocarbon 52:717-726

Peltola A (2014) Metsätilastollinen vuosikirja 2014

Peltola H, Kellomaki S, Hassinen A, Granander M (2000) Mechanical stability of Scots pine, Norway spruce and birch: an analysis of tree-pulling experiments in Finland Forest Ecology And Management 135:143-153

Peltola H, Kellomäki S, Väisänen H, Ikonen V-P (1999) A mechanistic model for assessing the risk of wind and snow damage to single trees and stands of Scots pine, Norway spruce, and birch Canadian Journal of Forest Research 29:647-661

Ryan MG, Yoder BJ (1997) Hydraulic limits to tree height and tree growth Bioscience 47:235-242 doi:10.2307/1313077 
Sæbø A, Benedikz T, Randrup TBJUF, Greening U (2003) Selection of trees for urban forestry in the Nordic countries 2:101-114

Schiestl - Aalto P, Kulmala L, Mäkinen H, Nikinmaa E, Mäkelä A (2015) CASSIA - a dynamic model for predicting intra - annual sink demand and interannual growth variation in S cots pine New Phytol 206:647-659

Scholz FG, Phillips NG, Bucci SJ, Meinzer FC, Goldstein G (2011) Hydraulic capacitance: biophysics and functional significance of internal water sources in relation to tree size. In: Size-and agerelated changes in tree structure and function. Springer, pp 341-361

Shinozaki K, Yoda K, Hozumi K, Kira T (1964) A quantitative analysis on plant form - The pipe model theory. I - Basic analyses. Japanese Journal of Ecology 14:97-105

Skatter S, Kucera B (2000) Tree breakage from torsional wind loading due to crown asymmetry Forest Ecology Management 135:97-103

Spatz H-C, Bruechert F (2000) Basic biomechanics of self-supporting plants: wind loads and gravitational loads on a Norway spruce tree Forest Ecology Management 135:33-44

Stull RB (2012) An introduction to boundary layer meteorology vol 13. Springer Science \& Business Media,

Van Pelt R, Sillett SC, Kruse WA, Freund JA, Kramer RD (2016) Emergent crowns and light-use complementarity lead to global maximum biomass and leaf area in Sequoia sempervirens forests Forest Ecology Management 375:279-308

Vogel S (2013) Comparative biomechanics: life's physical world. Princeton University Press,

West GB, Brown JH, Enquist BJ (1999) A general model for the structure and allometry of plant vascular systems Nature 400:664-667

Wicker L, Skamarock WC (2002) Time-splitting methods for elastic models using forward time schemes Monthly weather review 130:2088-2097

Woodruff DR (2013) The impacts of water stress on phloem transport in Douglas-fir trees Tree physiology 34:5-14 

and natural conditions Journal of Biology, Osaka City University 14:107-129

725

726 


\section{Figure captions}

Figure 1. Storm-bent height of the five felled trees plotted against $d_{1.3}$ and a fitted linear regression model. $\mathrm{R}^{2}$ is the coefficient of determination.

Figure 2. Storm-bent height of the five felled trees multiplied by their sail area (projected area of trunk, branches and leaves) plotted against the cube of $d_{1.3}$ and a fitter linear regression model. $\mathrm{R}^{2}$ is the coefficient of determination.

Figure 3. An example of how we computed the bending moments from the forces caused by gravity and wind blowing from left to right. The "dashed" line represents storm-bent Tree3 with 18 uneven segments visible out of its 35 segments. The vectors show how we computed the moment caused by the $11^{\text {th }}$ topmost segment to the $3^{\text {rd }}$ lowest segment (both of which are highlighted with a thicker red line).

Figure 4. Sail area and winds in a gust at various heights in the canopy and just above.

Figure 5. The five felled trees shown as storm-bent. The number of the poorly visible topmost segments that have bent to horizontal ranges from 4 (Tree5) to 11 (Tree2). The green, red and blue horizontal lines represent force vectors caused by wind in the dense simulation on each segment, with the colour indicating whether the drag is caused by the trunk, branches or leaves. The vertical lines represent forces caused by gravity. The length of vertical vectors from the lowest segments is not shown. The bottom end of a vector is -5.7 
751 above.

752

753 Figure 6. The relative importance of the bending moment caused by gravity acting on

754 segments above the segment in question.

755

756 Figure 7. The dimensions of five felled tree trunks (solid black) and dimensions sufficient to

757 withstand wind and gravity (dotted and dashed lines) in a meteorological situation that

758 causes a mean wind above the canopy of the dense stand $(w)$ of $10.2 \mathrm{~m} \mathrm{~s}^{-1}$, which is the

759 critical speed that nearly breaks Tree4. The heights on vertical axis and diameters on the

760 horizontal axis are not proportional. Diameters at a height of $1.3 \mathrm{~m}$ are given in the bottom.

761 The critical above-canopy wind speed for the dense stand is indicated inside the trunks. The

762 lowest living branches were at heights of 11.2-14.5 m. 